\title{
Assessment on Functionality and Viability of B cells Following Repetitive Dosage Administration of Ethanolic Extracts of Andrographis paniculata on Streptozotocin-induced Diabetic Rats.
}

\author{
Abdul Razak Ka, Mariam A $\mathrm{A}^{\mathrm{b}}$, Amirin $\mathrm{S}^{\mathrm{b}}$ and Mohd Zaini $\mathrm{A}^{\mathrm{b}}$ \\ ${ }^{a}$ Kulliyah of Pharmacy, International Islamic University Malaysia, Kuantan, Malaysia \\ b School of Pharmaceutical Sciences, Universiti Sains Malaysia, Penang, Malaysia
}

\begin{abstract}
Introduction: The study was done at the aim to assess the functionality and viability of the $B$ cells of the streptozotocin-induced diabetic rats model following repetitive dosage of administration of ethanolic extracts of Andrographis paniculata. Materials and Methods: The diabetic rats were treated with the extracts for fourteen days and at the dose given was $500 \mathrm{mg} / \mathrm{kg}$ twice daily. The assessments were made on fasting blood glucose, insulin, and immunohistochemical aspect of B cells before and after treatment. Results: The results showed that there was a significant reduction on fasting blood glucose levels in metformin, 95\% and $50 \%$ ethanolic plant extracts-treated groups but on insulin level only $95 \%$ and $50 \%$ ethanolic extracts-treated groups gave a significant reduction $(p<0.05)$. Immunohistochemical assessments revealed that all extract groups and metformin-treated were significantly increased in the population of $B$ cells $(p<0.01)$. Conclusion: This study revealed that the plant extracts showed an ability to promote the growth or rejuvenate the STZdestructed $B$ cells and in turn lower the blood glucose level.
\end{abstract}

KEYWORDS: Andrographis paniculata, diabetes mellitus, streptozotocin-induced rats, B cells, hyperglycaemia

\section{INTRODUCTION}

Andrographis paniculata Nees (AP), a member of plant family of Acanthacaea, grows abundantly in southeastern Asia, from India to Indo-China, the northern Malay Peninsula and Java. ${ }^{1}$ It is vernacularly known as King of Bitter, The Creat, Kariyat, Hempedu Bumi and Pokok Cerita. It is an erect and branched plant with lanceolate green leaves growing to a height of $60-70 \mathrm{~cm}$. The plant has been used in the Indian Pharmacopoeia and Traditional Chinese medicine and used to treat upper respiratory and gastrointestinal tract infections, fever, sore throat and a variety of other chronic and infectious diseases. In the Peninsular of Malaysia there is evidence of practice that the plant is useful in curing diabetes. ${ }^{2}$ Local inhabitants, especially in certain rural areas of northern region of Malaysia peninsular, they strongly believed that the decoction of the plant would act as a potent folk medicine in the treatment of diabetes mellitus. ${ }^{3}$

Preliminary studies showed that the aqueous extract of AP lower blood glucose level in diabetic rat models acutely. ${ }^{3,4}$ Other studies showed that multiple doses

Corresponding author;

K. Abdul Razak

Kulliyyah of Pharmacy

International Islamic University Malaysia

25200 Kuantan, Pahang, Malaysia

e-mail:drazak@iiu.edu.my of ethanol extract of the plant manage to lower blood glucose level in diabetic rats. ${ }^{5}$ While one study reported that the $20 \%$ of ethanol extract of the plant has acute antihyperglycaemic effect on normal rat in Intraperitoneal Glucose Tolerance test (IPGTT) but not in diabetic rats. ${ }^{6}$ Recently, a study proved that andrographolide, an active compound isolated from this plant reduced the blood glucose levels in diabetic rats when challenged with oral administration of starch and sucrose. ${ }^{7}$ The study also showed that the plant has an inhibitory action on a- glucosidase and a- amylase inhibitory activity.

This study is meant to elucidate the antihyperglycaemic effect of different percentage of ethanol extracts of the plant on diabetic rat following repetitive dosage administration of different percentage of ethanolic extracts of AP. The study also trying to reveal the effect of repetitive doses on the Streptozotocindestructed B cells viability. Thus the objectives of the study are:

1. To study the fasting blood glucose and insulin levels on the streptozotocin-induced diabetic rats following treatment of twice daily of $500 \mathrm{mg} / \mathrm{kg} \mathrm{AP}$ extracts for fourteen days.

2. To do immunohistopathological assessment on the $B$ cells of the streptozotocin-induced diabetic rats following treatment of twice daily of $500 \mathrm{mg} / \mathrm{kg} \mathrm{AP}$ extracts for fourteen days. 


\section{MATERIALS AND METHODS}

\section{Plant Material}

The plant material used in this study was dried aerial and leaves part of the plant standardized and supplied by Malaysian Research on Agriculture Development Institute (MARDI) Telong, Kota Bharu Kelantan and authenticated as Andrographis paniculata.

\section{Preparation of Extract}

The dried plant was ground to a powder form using a milling machine. The dried powder was then divided equally into four groups of different solvent system. In preparing the plant extracts, all procedures are similar except in the percentage of ethanol used as a solvent. The solvents used were $95 \% \mathrm{v} / \mathrm{v}$ of Ethanol, $50 \% \mathrm{v} / \mathrm{v}$ of Ethanol, $20 \% \mathrm{v} / \mathrm{v}$ of Ethanol and Water.

The dried powder was continuously being extracted with solvent in the hot bath at temperature of $60 \mathrm{oC}$ for three consecutive days. Then the extract was filtered and evaporated under vacuum to dryness. In order to achieve complete dryness the extract was placed in the oven at $600 \mathrm{C}$ until the weight is constant.

The yield of the extract (\%w/w) of 95\% Ethanol, 50\% Ethanol, 20\% Ethanol and water extracts were $8.70 \%$, $11.46 \%, 13.29 \%$ and $10.03 \%$ respectively.

\section{Experimental Animal}

Normoglycaemic Sprague-Dawley rats used in this study were obtained from the animal house of the School of Pharmaceutical Sciences, Universiti Sains Malaysia, Penang. The animals were kept in plastic cages and maintained on standard laboratory animal diet with water ad libitum.

\section{Sample collection}

\section{Fasting Blood Glucose level}

A drop of blood was collected from the tail nick and the blood glucose levels were determined by clinical glucometer (Accutrend Advantage II Clinical Glucose meter by Roche $\left.{ }^{\circledR}\right)$. All samples were taken from overnight fasted rat in order to reflect a fasting blood glucose level.

\section{Insulin assay}

The blood was drawn out from the tail nick by using capillary tube and spun it in the heamatocrit centrifuge. The plasma then collected and stored at $-20 \mathrm{oC}$. A commercial ELISA kit of rat insulin (Crystal Chem Inc, IL, USA) was used in determining level of plasma insulin.

\section{Histological specimen}

The specimen section was taken from the tail of pan- creas of the rats after fourteen days treatment. The specimens then immediately were fixed with $10 \%$ formalin for 48 hours before dehydration process and embedded in paraffin. The embedded tissues then cut into $5 \mu \mathrm{m}$ slices and fixed on Poly-o-lysin-treated glass slide. The tissues then rehydrated and were immunostained before being dehydrated and mounted with DPX ${ }^{\circledR}$ and cover slip.

The basis of immunohistochemical staining is to detect insulin in the viable and normal B cells. A guinea-pig polyclonal antibody of rat's insulin (DAKO, Glostrup, Denmark) and the avidin-biotin complex ( $A B C)$ method, by using a Vectastain ${ }^{\circ} A B C$ kit (Vector laboratories, Burlingame, $C A$ ) were utilized. Complexes were visualized by a reaction with peroxidase substrate solution containing 3, 3 -diaminobenzidine tetrahydrochloride (DAB) (Zymed Laboratories, San Francisco, CA) and hematoxylin to counter staining the nuclei.

A computerized image analyzer (Leica ${ }^{\circledR}$ microsytem Qwin plus) was used to calculate the immunological stained (insulin-containing $B$ cells) area and the size of the Islet of Langerhans. The percentage of immuno-stained area was then been determined. Fifteen slides from five different rats per each group were analyzed.

\section{Drugs used}

Reference drug that had been utilized as positive control was Metformin 500mg/kg (as 500mg tab supplied by $U_{P H A}{ }^{\circledast}$ ). Streptozotocin $65 \mathrm{mg} / \mathrm{kg}$ in (supplied by SIGMA ${ }^{\circledR}$ ) administered intraperitonelly was used to induce diabetes in rats.

\section{Experimental Setup}

\section{Assessment of destruction of B cells.}

Twelve Sprague-Dawley rats (200 - 250g) of either sex randomly divided into two groups. One group was assigned as normal group where there was no induction. The other group was induced intraperitoneally with streptozotocin at the dose of $65 \mathrm{mg} / \mathrm{kg}$ of body weight. The dose was considered as a moderate dose. 8 After three days of induction, fasting blood sugar was recorded and rats with a reading above $15 \mathrm{mMol} / \mathrm{L}$ were considered diabetic. All rats, normal and successfully induced diabetic rats were then sacrificed and histological specimen was taken.

\section{Fourteen days of twice daily dose experiment.}

Thirty six Sprague-Dawley rats (200 - 250g) of either sex were successfully induced with Streptozotocin, $65 \mathrm{mg} / \mathrm{kg}$ intraperitoneally. After three days of induction, fasting blood sugar was recorded and rats with a reading above $15 \mathrm{mMol} / \mathrm{L}$ were considered diabetic. The diabetic rats were randomly and equally divided into six groups. They were orally treated with different treatment twice daily for fourteen days. All treatment was given at same administration volume that 
is $0.1 \mathrm{ml}$ per gram of body weight. The first group was a control group and was treated with distilled water. The second group was metformin-treated. The other four groups were treated with plant extracts of $95 \%$, $50 \%, 20 \%$ and $0 \%$ (water) ethanol extracts.

The baseline or pretreatment reading of fasting blood glucose level as well as insulin level was recorded after three days of successful induction. The final or the post-treatment of both readings were taken on the 15 th day of treatment. Then the rats were sacrificed and histological specimens were taken.

\section{Statistical analysis}

All data were expressed as mean \pm SEM. The means differences between pre and post treatment were analyzed by paired t-test. In comparing between groups, the means differences among the groups were statistically analyzed by one-way ANOVA. Dunnett t-test was chosen as a post hoc test where it treats one group as a control and compared all other groups against it.

\section{RESULTS}

\section{Assessment of destruction of B cells.}

The fasting blood glucose level of normal and streptozotocin-induced diabetic rat were $3.93 \pm 0.10 \mathrm{mMol} / \mathrm{L}$ and $20.76 \pm 0.35 \mathrm{mMol} / \mathrm{L}$ respectively (Table I). The insulin level of normal and streptozotocin-induced diabetic rat were $117.63 \pm 3.79 \mathrm{pg} / \mathrm{ml}$ and $57.45 \pm 1.97$ $\mathrm{pg} / \mathrm{ml}$ respectively (Table $\mathrm{I}$ ). Immunostained $B$ cells were brown in colour (Figure 1). Percentage area of $B$ cells against the size of the Islet of Langerhans in normal rat and streptozotocin-induced diabetic rat were $80.92 \pm 1.49 \%$ and $8.53 \pm 1.49 \%$ respectively. Therefore, the percentage of destruction of $B$ cells following the induction by streptozotocin $(65 \mathrm{mg} / \mathrm{kg}$ intraperitoneally) was $89.46 \%$.

Table I. Fasting blood glucose, insulin level and immunostained area of $B$ cells in normal and streptozotocin-induced diabetic rats.

$n=6$

\begin{tabular}{|l|c|c|c|}
\hline \multicolumn{1}{|c|}{ Type of Rat } & $\begin{array}{c}\text { Fasting BloodGlucose } \\
(\mathrm{mH} H \mathrm{l} / \mathrm{L})\end{array}$ & $\begin{array}{c}\text { Insulin Level } \\
(\mathrm{pg} / \mathrm{mL})\end{array}$ & $\begin{array}{c}\text { Immunostained area } \\
(\%)\end{array}$ \\
\hline Nomal & $3.93 \pm 0.10$ & $117.63 \pm 3.79$ & $80.92+1.49$ \\
\hline Induced Diabetic & $20.76 \pm 0.35$ & $57.45 \pm 1.97$ & $8.53 \pm 1.48$ \\
\hline
\end{tabular}

\section{DISCUSSION}

The use of streptozotocin in inducing diabetic rat was widely utilized due to it specificity in destructing only the $B$ cells of Islets of Langerhans. ${ }^{8,9}$ The intermediate dose of $65 \mathrm{mg} / \mathrm{kg}$ intraperitoneally manages to induce the diabetic state and the rats were able to survive without insulin supplement up to fourteen days. This finding was corresponded with earlier studies. ${ }^{10,11}$ This study also showed that the dose was able to destruct
Figure 1. Photograph of Islets of Langerhans and the immunostained area of B cells (40X10 magnification).

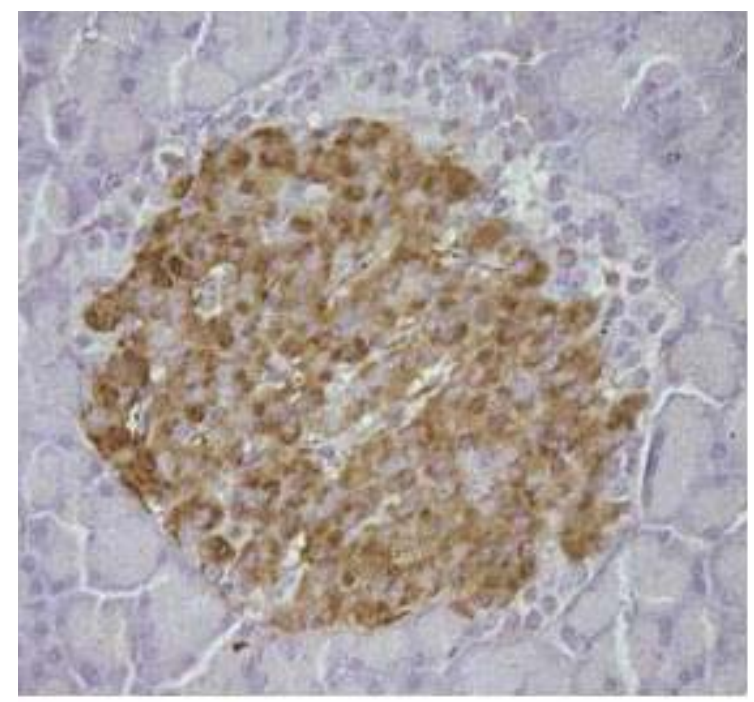

A) Normal

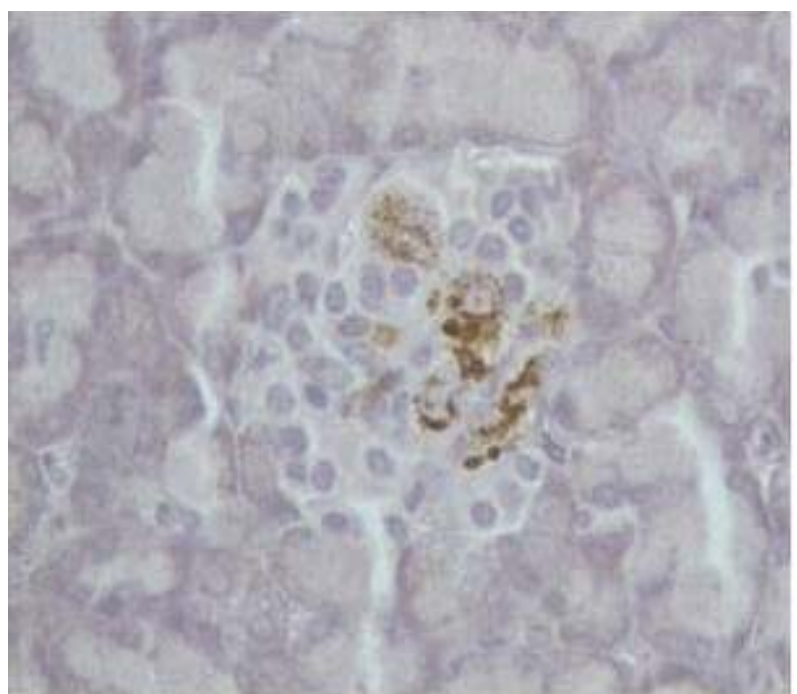

B) Diabetic

$89.46 \%$ of $B$ cells and the rats manage to survive with $10.54 \%$ of the remnant of functional $B$ cells. This remnant $B$ cells adequately secrete insulin of $57.45 \mathrm{pg} / \mathrm{mL}$ to maintain the blood glucose level at $20.76 \mathrm{mMol} / \mathrm{L}$. A deduction also can made from Table I, that there is increase in secretion of insulin per unit of immunostained area as in normal it is $1.45 \mathrm{pg} / \mathrm{mL} /$ unit area and in diabetic it is increased to $6.73 \mathrm{pg} / \mathrm{mL} /$ unit area. This may be due to some compensatory mechanism in maximizing insulin production by the remnant $B$ cells and this makes possible to maintain the survival of the induced diabetic rat with limited functional $B$ cells.

On fasting blood glucose level, after a repetitive doses regime, the post-treatment level of metformin, 95\% and $50 \%$ ethanol extract-treated groups were significantly lower if compared with the pre-treatment level (Figure 2). This result was in tandem with the previous study in addition it also shows that $50 \%$ ethanol 


\section{Fourteen days of twice daily dose experiment}

The rats which were been treated with $95 \%$ and $50 \%$ ethanol extracts showed significant decrement of fasting blood glucose when compared to the pre-treatment level $(p<0.05)$ (Figure 2$)$.

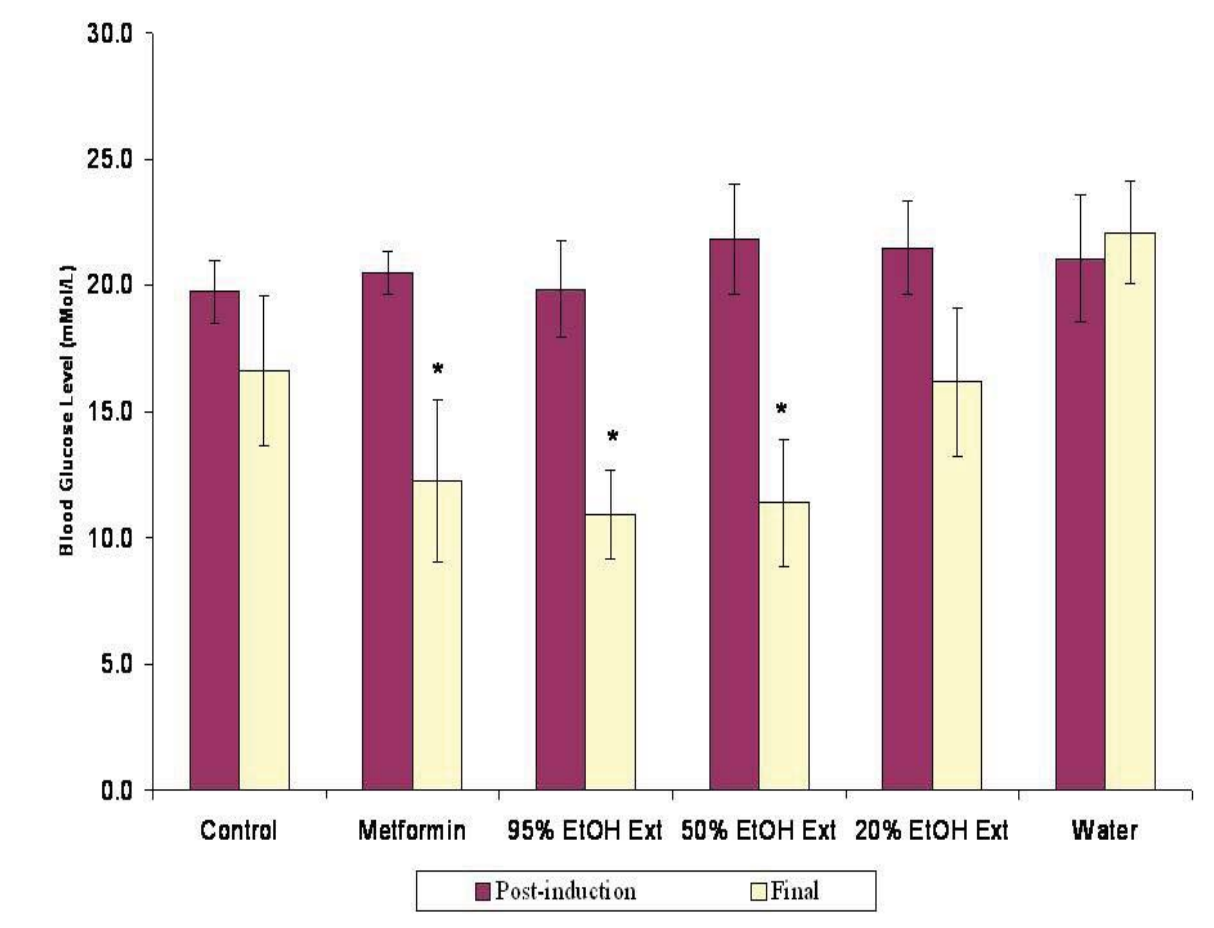

$n=6 ;{ }^{*} p<0.05$

Figure 2. Effect of different percentage of ethanol extracts at the dose of $500 \mathrm{mg} / \mathrm{kg}$ b.d., distilled water (control) and Metformin at the dose $500 \mathrm{mg} / \mathrm{kg}$ b.d. on fasting blood glucose (mean \pm SEM).

The insulin level also significantly lower when was compared to the pre-treatment level in the $95 \%$ and $50 \%$ ethanol extracts $(\mathrm{p}<0.05)$ (Figure 3$)$. All treatment and control (without treatment) groups showed an increment of number of viable $B$ cells when compared with post induction (before treatment) group. Statistical analysis revealed all treatment groups were significant when compared with control or non-treated group $(p<0.01)$ (Figure 4).

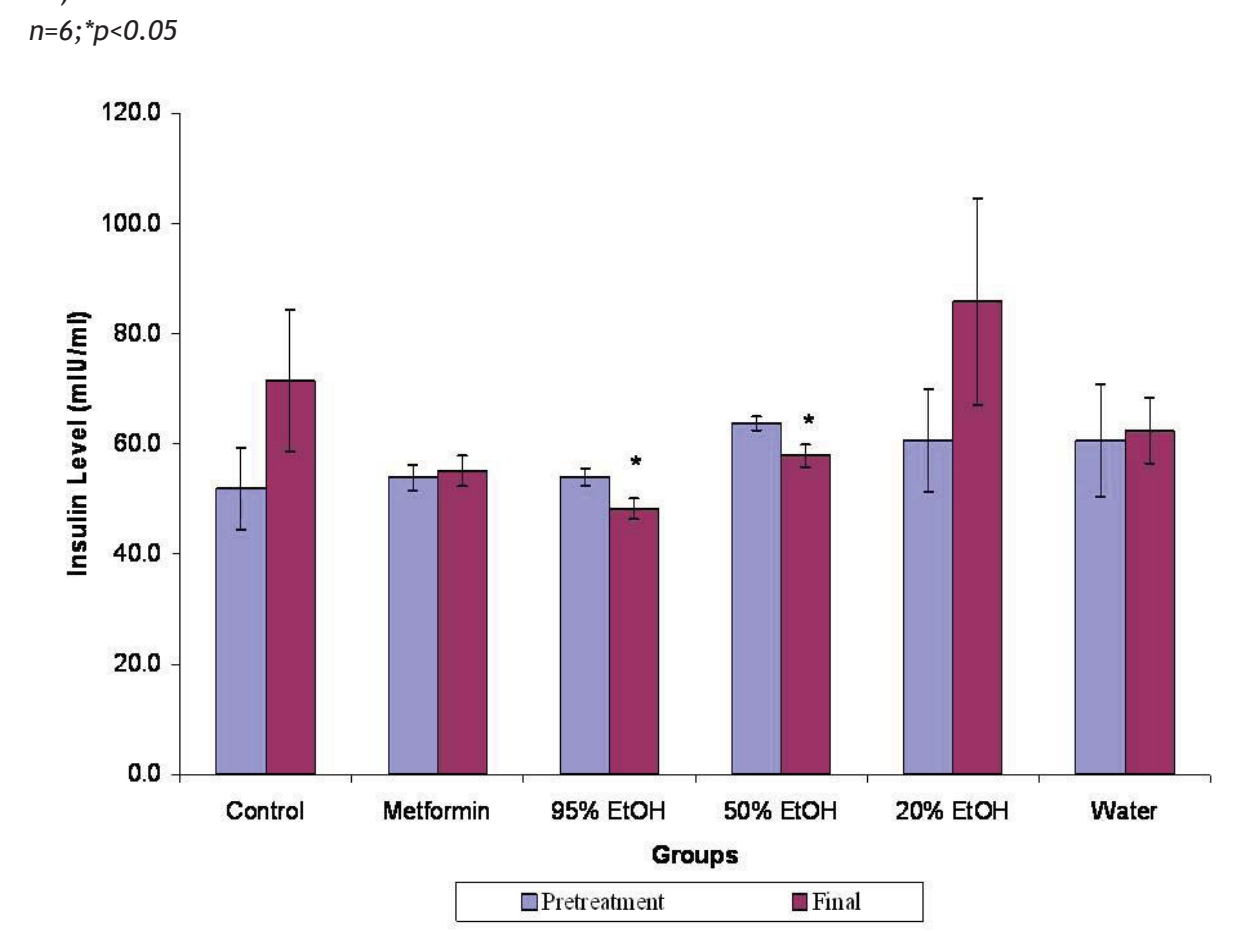

Figure 3. Effect of different percentage of ethanol extracts at the dose of $500 \mathrm{mg} / \mathrm{kg}$ b.d., distilled water (control) and Metformin at the dose $500 \mathrm{mg} / \mathrm{kg}$ b.d. on insulin level (mean $\pm S E M$ ). 


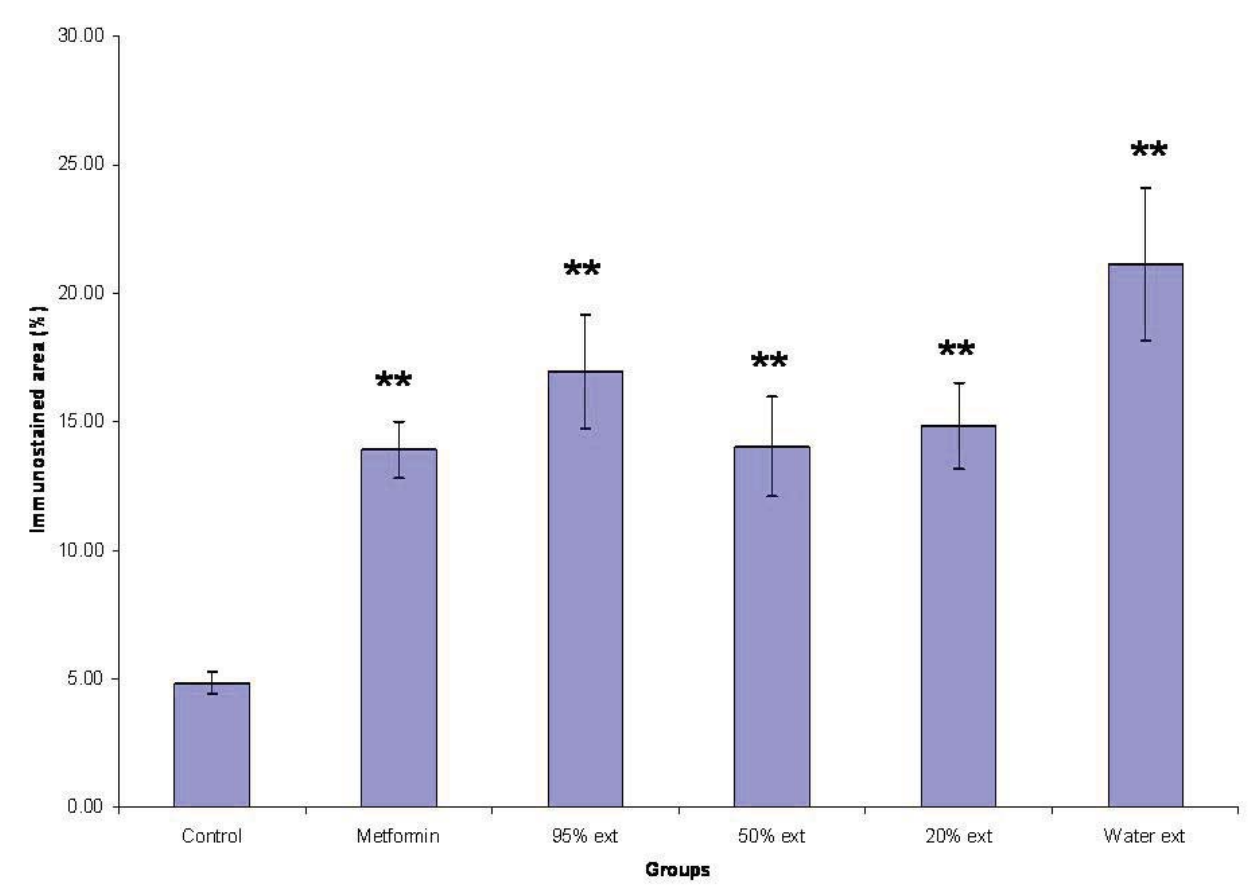

$n=15 ; * * p<0.01$

Figure 4. The effect of 14 days treatment of Metformin, , 95\%, 50\%, 20\% ethanol and water extract and nontreated (control) on STZ-induced diabetic SD rats' B cells viability.

extracts has a same effect. ${ }^{5}$ On the other hand, the insulin levels were significantly lower in $95 \%$ and $50 \%$ ethanol extract-treated group but not in metformintreated group. This shows that the extract does not stimulate the production of the insulin. The lower insulin reflects the lower blood glucose level as their relationship is physiologically dynamic. The result above represents a cross sectional of situation where there is low blood glucose and low insulin level. This situation also may be due to the increase sensitivity of peripheral receptors toward insulin following the administration of metformin and the extracts. The result in metformin group where metformin a known antidiabetic drug that does not stimulate insulin release. The blood glucose level in metformin group was not lower enough to cause significantly low insulin when compared with $95 \%$ and $50 \%$ ethanol extract-treated group.

The immunohistochemical assessment reveals all extract have a capability to promote or enhance the regrowth of destructed $B$ cells (Table II). The result also reveals that $B$ cells are capable to rejuvenate and this ability was seen in control or distilled water-treated group. However the effect was not significant if compared with extracts and metformin-treated group (Figure 4).

Table II. Percentage of Increment of immunostained area of control, Metformin, 95\%, 50\%, 20\% and watertreated groups within pre-treatment and post-treatment

\begin{tabular}{|l|c|}
\hline Groups & Percentage of Increment \\
\hline Control & 56.68 \\
\hline Metformin & 162.94 \\
\hline 95\% Ethanol extract & 198.83 \\
\hline $50 \%$ Ethanol extract & 164.52 \\
\hline 20\% Ethanol extract & 173.92 \\
\hline Water extract & 247.67 \\
\hline
\end{tabular}

\section{CONCLUSION}

In conclusion, it seems that the lowering of blood glucose effect was not due to direct stimulation of insulin. It may be due to extrapancreatic mechanisms or other indirect mechanism such as inhibition of glucose absorption. ${ }^{7}$ The study inevitably suggests that the most probable indirect mechanism of the extracts is by rejuvenating or promoting the re-growth of $B$ cells. However further studies on extrapancreatic mechanisms such as an increase glucose intake in muscle and adipose tissue, increase tissue receptor sensitivity, or inhibition of gluconeogenesis would adequately give more explanation of the effect of the ethanolic extracts of the plant. The $20 \%$ ethanol extract which was reported earlier has an antihyperglycaemic in IPGTT on normal rat should be further studied. ${ }^{6}$ The future study on how the underlying mechanism of the extracts able to rejuvenate the $B$ cells would give a great impetus in understanding not only the usage of the plant but the diabetes mellitus itself. 
On the other paradigm, the study on bioactivity guided isolation of the active ingredient/s from the ethanolic extract of Andrographis paniculata which is responsible in producing the effect would give additional benefit.

\section{ACKNOWLEDGEMENTS}

This research was supported by a grant of Ministry of Science, Technology and Environment of Malaysia (MOSTE).

\section{REFERENCES}

1. Perry LM. Medicinal plants of east and Southeast Asia. Massachusett: The MIT Press, 1980.

2. Burkill LH. A Dictionary of the economic products of the Malay Peninsula. Kuala Lumpur: Ministry of Agriculture and Cooperatives Malaysia, 1966: 2202-5

3. Ahmad M, Asmawi MZ. Effects of Andrographis paniculata on the blood glucose levels in normoglycaemic rats. Proceedings of the International Congress on Traditional Medicine and Medicinal Plants, Bali Indonesia 1990.

4. Noor H, Aschroft SJH. Natural hypoglycaemics: fact and fantasies. Diabet Med 1989; 33:621A

5. Zhang XF, Tan BK. Antihyperglycamic and antioxidant properties of Andrographis paniculata in normal and diabetic rats. Clin Exp Pharmacol Physiol 2000; 27:358-68

6. Abdul Razak K, Mariam A, Amirin S, Mohd Zaini A. Antihyperglycaemic effect of different percentage of ethanolic extracts of Andrographis paniculata in normal and diabetic rats. Abstract book of the 5th Scientific Congress Federation of Asian \& Oceanian Physiological Societies (FAOPS) 2002;131

7. Rammohan S, Asmawi MZ, Amirin S. Effect of andrographolide and ethanol extract of Andrographis paniculata on liver glycolytic, gluconeogenic, and lipogenic enzymes in a type 2 diabetic rat model. Pharmaceutical Biology 2008; 46:772-80

8. Junod A, Lambert AE, Orci L, Pictet R, Gonet AE, Renold AE. Studies of the diabetogenic action of streptozotocin. Proc Soc Exp Bio Med 1967; 126:201-5

9. Frode TS, Medeiros YS. (). Animal models to test drugs with potential antidiabetic activity. J Ethnopharmacol 2008; 115:173-83

10. Junod A, Lambert AE, Stauffacher W, Renold AE. Diabetogenic action of streptozotocin: relation of dose to metabolic response. J Clin Invest 1969; 48:2129-39

11. Ar'Rajab A, Ahren B. Prevention of hyperglycaemia improves long term result of islet transplantation in streptozotocin-induced rats. Pancreas 1992; 7:435-42 